\title{
A within-person approach to the relation between quality of task motivation, performance and job satisfaction in everyday working life
}

Koen Hogenelst ${ }^{1}$, Roos Schelvis ${ }^{2}$, Tanja Krone ${ }^{3}$, Marylene Gagné ${ }^{4}$, Matti Heino ${ }^{5}$, Keegan Knittle $^{5}$, Nelli Hankonen ${ }^{5}$

${ }^{1}$ Department of Training and Performance Innovations, The Netherlands Organisation for Applied Scientific Research (TNO), Soesterberg, The Netherlands

${ }^{2}$ Department of Human Resources, Erasmus University Rotterdam, The Netherlands

${ }^{3}$ Department of Risk Analysis for Products in Development, The Netherlands Organisation for Applied Scientific Research (TNO), Utrecht, The Netherlands

${ }^{4}$ Faculty of Business and Law, Future of Work Institute, Curtin University, Australia

${ }^{5}$ Faculty of Social Sciences; University of Helsinki, Finland

Corresponding author:

Koen Hogenelst, PhD E-mail: koen.hogenelst@tno.nl

Key words:

Motivation - Productivity - Job Satisfaction - Ecological Momentary Assessment - Within person - Self-Determination Theory 


\section{Funding}

KH, TK and RS were supported by the TNO Work \& Health Research Program, which is funded by the Ministry of Economic Affairs and supported by the Dutch Ministry of Social Affairs and Employment, program number 19.204.1-3. KK, MH, and NH's contributions to this work were funded by the Academy of Finland (project grants \#295765 and \#285283 to principal investigator $\mathrm{NH})$. 


\begin{abstract}
Previous research on work-related motivation and work-related outcomes generally shows that autonomous forms of motivation are associated with higher performance and job satisfaction, whereas controlled forms of motivation are generally linked to worse outcomes. These relationships are largely based on between-persons data from cross-sectional studies or longitudinal studies with few measurement points. However, motivation quality, performance, and job satisfaction can vary considerably from day to day, both between and within individuals. The present study therefore combines between-persons and within-persons approaches to study the relationships between motivation, performance, and job satisfaction. Nineteen white-collar workers participated in the study. With a default protocol of 30 working days, an ecological momentary assessment app prompted participants five times a day to report their autonomous and controlled motivation for work tasks and their productivity and job satisfaction at the end of each day. Fourteen participants gathered sufficient data to compute within-person relations and individual networks. At the between person level, autonomous motivation was positively associated with productivity, whereas no association with job satisfaction was detected. No associations were detected between controlled motivation and productivity or job satisfaction. At group level within persons, (a) motivation during work tasks (autonomous or controlled) was not associated with self-reported productivity or job satisfaction at the end of that day, (b) self-reported productivity at the end of a day was negatively related to next day autonomous and controlled motivation, and (c) end of day job satisfaction was positively related to next day controlled motivation, but not autonomous motivation. Individual network analyses indicated considerable interindividual heterogeneity, especially in the relationships between motivation and job satisfaction. In conclusion, these findings point to significant variability in the observed relations between motivation, performance and job satisfaction, and highlight the added value of a within person
\end{abstract}


approach and individual networks in addition to between-persons approaches. The implications of these findings for occupational wellbeing research are discussed.

\section{Introduction}

Employees' work motivation is of crucial importance to the success of organizations and societies, as well as to the well-being of individuals (Kanfer et al., 2017). While motivation is often conceptualized as a single quantity (i.e. one can be unmotivated, highly motivated or somewhere in between), Self-Determination Theory (SDT; Ryan \& Deci, 2000) proposes that motivation can take on different qualities, which are predictive of behavior and outcomes across various contexts (Gagné et al., 2015; Ng et al., 2012). According to SDT, individuals are innately active and growth-seeking, having autonomous, self-determined motivational regulations (Ryan \& Deci, 2000). An autonomously motivated individual (i.e., motivated through pleasure, interest, and/or meaning) performs an activity for its own sake, or because it is deemed personally important, resulting in high quality performance of the behavior (Gagné \& Deci, 2005; Howard et al., 2016; Kuvaas et al., 2017). In contrast to selfdetermined (autonomous) work motivation, work behavior performed to obtain rewards or avoid punishments, or for self-worth related concerns, expresses controlled motivation, and results generally in qualitatively worse outcomes (Vansteenkiste et al., 2007; Stenius, 2016, Gagné et al., 2019).

\section{Motivation and performance}

Previous research illustrates the relevance of SDT-based motivations when studying work performance. For example, Kuvaas et al. (2017) studied the extent to which both intrinsic and extrinsic motivation affected supervisor-rated work performance, among other work related outcomes. Intrinsic motivation was defined and assessed as the desire to perform an activity for its own sake, in order to experience the pleasure and satisfaction inherent in the activity. Extrinsic motivation, in contrast, was conceptualized and assessed as the degree to 
which work motivation was contingent on the existence of tangible incentives. Thus, intrinsic motivation and extrinsic motivation may be seen as more narrow concepts than respectively autonomous and controlled motivation (see also Cerasoli et al., 2014). Across their two studies, it was consistently found that intrinsic motivation was positively associated with work performance, whereas extrinsic motivation was negatively related or unrelated to work performance (Kuvaas et al., 2017). These findings are largely in line with a review by Gagné and Deci (2005) and a meta-analysis by Cerasoli et al. (2014) on the quality of motivation and work performance. As the vast majority of studies concerned used a between-person approach, they inform why one person performs better at work than others, for example. In contrast, to assess why one person performs better on some days than on other days, a withinperson approach is needed. In fact, theories of within-person performance variability converge on the contention that job performance is dynamic rather than static, underlining the importance of a within-person approach to studying job performance (Dalal et al., 2014; 2020). In addition, motivation has been shown to exhibit considerable day-to-day variation (e.g. Levesque and Brown, 2007). Whereas personality and affect have previously been shown to be relevant within-person antecedents of performance on a day-to-day basis (e.g., Judge et al., 2014; Debusscher et al., 2016; Merlo et al., 2018), to our knowledge, no studies have assessed the quality of motivation as a within-person antecedent of performance on a day-to-day basis. Studying this association within persons and at the individual level may potentially reveal different outcomes compared to between person approaches. Furthermore, studying this on a daily basis also allows to include other relevant variables that vary from day to day and are known to affect productivity and motivation, such as sleep quality (Kühnel et al., 2016; 2017).

\section{Motivation and job satisfaction}


Similar to performance, distinguishing between different SDT-based qualities of motivation is also relevant for employee well-being, including job satisfaction (Deci et al., 2017). Several survey-based studies indicate that autonomous is more strongly and positively related to job satisfaction than controlled motivation (Richer et al., 2002; Millette and Gagné, 2008; Gagné et al., 2010). Yet also for job satisfaction, scholars have acknowledged that it too has a state-like component, in addition to a dispositional or enduring component (Ilies \& Judge, 2002, 2004). Accordingly, studies have indicated that there is substantial day-to-day variation in job satisfaction experienced, which also impacts organizational behavior (Bowling et al., 2005). The traditional between-person research paradigm with pre- and (one or more) follow-up measurements does not allow us to study these variations, as has been noted by others (Ilies \& Judge, 2002). Instead, series of repeated measurements per individual and within-person analyses approaches are needed. In applying such a design, Ilies and Judge (2002) found that over one third (36\%) of the differences in summated means of reported job satisfaction (27 respondents, four times a day for 19 working days) could be ascribed to differences within individuals. Part of this variation has been ascribed to individual's affective state (Ilies et al., 2015). Yet, we presume that these daily fluctuations could also be induced by tasks that need to be done in the workplace and an assessment of how motivated one is to perform these tasks.

\section{Frequent day-to-day measurements and within person approach}

To understand and promote performance and job satisfaction of workers, several researchers have suggested taking an individualized approach (Binnewies et al., 2010; Dalal et al., 2014; Bakker, 2015; Ilies et al., 2015). However, methodological approaches of many of the previous studies in this research area have consisted of using questionnaire surveys administered once or a few times and have only examined between-persons associations between motivation and work-related outcomes (e.g., Richer et al, 2002; Otis \& Pelletier, 
2005; Gagné et al., 2015, Kuvaas et al, 2017). While such approaches certainly have their merits, they are limited in terms of providing group averages only, and conceal potentially high variability in different individuals, including temporal mechanisms within individuals. Conclusions based on between-persons group level data not necessarily generalize to individual participants, threatening the validity of conclusions drawn from typical research designs, also in psychological science (Fisher et al., 2018). Elucidating the relevant mechanisms at the individual as well as event level paves the way for personalized interventions to improve performance, e.g. by targeting timely and personally relevant motivational aspects, fulfilling basic needs, and adaptations in organizational processes. Fortunately, person-centered investigations of these questions are today enabled by daily life research methodologies (discussed below), novel technologies (e.g., mobile applications; Spruijt-Metz, Nilsen, \& Pavel, 2014) and sophisticated statistical methods (e.g. multilevel and time-series models, Hamaker, 2012; 2017). Above all, between-person and within-person approaches should be considered complementary, rather than competitive.

Ecological momentary assessment (EMA) (Stone and Shiffman, 1994), also known as experience sampling methodology (Csikszentmihalyi and Larson, 1992) or ambulatory assessment (Fahrenberg and Myrtek, 1996), is a structured daily life research method to assess how people think, feel, and behave in everyday environments (Mehl and Conner, 2012). A distinguishing feature of EMA is that it encompasses short, but frequent and repeated assessments (often >20) of variables of interest, providing intensive longitudinal data typically on a relatively short time-scale ranging from several days to multiple weeks. EMA has several advantages over more traditional methodologies, such as survey studies. First, as the data is collected during participants' daily life, findings from EMA studies closely represent real-life experiences. Hence, this methodology provides high ecological validity as findings generalize to the real world. Second, data are collected close in time to experience, 
thereby limiting recall bias. Third, as EMA involves frequent and repeated assessments, it provides a resolution that allows individual differences in temporal dynamics to be analyzed. Simultaneous, frequent, and repeated assessments of different variables of interest, such as task-related motivation versus performance and job satisfaction on a day-to-day basis, additionally provide the opportunity to investigate dynamic associations between these variables, within individuals.

Studying the association between task-related motivation and productivity or job satisfaction in day-to-day life at the event-level may potentially reveal different outcomes compared to previous between person approaches (Gagné and Deci, 2005; Cerasoli et al., 2014; Kuvaas et al., 2017). It is not self-evident that the associations of these constructs on the general level would translate into lower-time scale associations, as the general level evaluations are based on more encompassing evaluations rather than moment-to-moment granular tasks. Regarding motivation, this can be further explained in light of goal theory, as it is now well-accepted that goals are at the heart of motivation (Unsworth et al., 2011). According to goal hierarchy theory, goals exist in a hierarchy with higher-order, more abstract, long-term goals (values or identities) versus more concrete day-to-day task goals (Cropanzano et al., 1993; Unsworth et al., 2011). Thus, it could be that individuals have different goals or foci in mind when asked "why do you do this job" (value or identity; most previous research) versus "why do you do this task right now" (task level; present study). This also relates to other goal theories, such as Gollwitzer's action phases of deliberation (e.g., desires, higher-order motivation) and implementation (e.g., task-related motivation) (Gollwitzer, 2012) and the role of desirability and feasibility considerations dominating in respectively distant (e.g., general work motivation) and near future activities (e.g., task related motivation) as described by Liberman \& Trope (1998). Taken together, when having a value or desire in mind, individuals might answer motivation questions differently from when they 
have a task to complete. As a consequence, the relation between task-related motivation and productivity or job satisfaction in day-to-day life might reveal different outcomes compared to previous between person approaches (Gagné and Deci, 2005; Cerasoli et al., 2014; Kuvaas et al., 2017).

In sum, previous research suggests that autonomous motivation is associated with higher performance and job satisfaction, and controlled motivation has generally been linked to worse outcomes (Kuvaas et al., 2017; Deci, Olafsen \& Ryan, 2017). These conclusions are mainly drawn from cross-sectional or longitudinal studies with few measurement times and typically describe between-persons associations between work-related motivation and workrelated outcomes. Studying the relevant mechanisms within persons and at the individual as well as event level may reveal different outcomes. This may contribute to theorizing of these processes and mechanisms, as well as affect practical applications, such as personalized interventions to improve motivation quality, performance and job satisfaction.

The present study investigated between persons, within persons, and the dynamics within persons over time, to what extent self-reported task-related motivation during a day is a predictor of self-reported performance (perceived productivity) and job satisfaction at the end of the day, as well as how the latter two predict next day task-related motivation. To do so, advances in mobile technology (mobile ecological momentary assessment) as well as data analytics (multilevel modeling and time-series analysis) were utilized. Due to the novelty of the approach and different levels of analyses with potentially different directions of effects, the present study was explorative in nature and no specific hypotheses were set.

\section{Methods}

\section{Ethical procedures}


This study was performed in accordance with the Declaration of Helsinki. The study protocol received a favorable review from the University of Helsinki Ethical Review Board in the Humanities and Social and Behavioural Sciences.

\section{Participants}

Nineteen white-collar workers with considerable variance in their work tasks were included. They were recruited from three different companies or organizations in Finland, and all had their main work roles in human resource management.

\section{Measures}

This study is part of a more comprehensive project assessing work-related motivation and work-related outcomes; an overview of all included measures and procedures can be found in supplementary material. Here, we describe only the measurements procedures used in the current study.

\section{Baseline questionnaire}

At baseline, demographic information including age, gender, highest education level attained, job title, number of years in current role and number of years within the organization were assessed in an online questionnaire via LimeSurvey.

\section{EMA}

Participants used a smartphone-based EMA app to record task-related motivation, productivity and job satisfaction, during working days (Monday through Fridays), for a default period of 30 working days, with the option to continue data collection as long as they wished. The app prompted participants five times over the course of each eight-hour working day: once at the start of the eight-hour work day, three random times during the eight hours, and once at the end of the eight-hour work day. During the eight-hour work period, participants could also open the app themselves to record extra measurement points (only once each 75 minutes and up to three completions). For each EMA recording, participants' 
reported their current work task (from a predefined list of work tasks, but they could also add their own) and how motivated they were to perform that task. More specifically, items for motivational regulation asked participants to rate the following statements, each starting with: "I am working on this task because": it is pleasurable (intrinsic); it is interesting (intrinsic); it is important to me (identified); someone else wants me to (external); the situation requires me to (external); I would feel guilty or anxious if I did not (introjected) (Ketonen et al., 2018). These statements were rated on visual analogue scales (VAS) with 49 increments, labeled from disagree to agree. In addition, the EMA recording at the start of the day also contained a question about previous night's sleep quality (VAS, rated from worst possible sleep to best possible sleep) (Cappelleri et al., 2009). The EMA recording at the end of the day also contained questions about productivity as an indicator of performance ("overall how productive were you at work today? " rated on a VAS from worst quality to best quality) (adapted from Schelvis et al., 2013) and job satisfaction ("overall how satisfied were you with your work day today? " rated on a VAS from very dissatisfied to very satisfied) (adapted from Scarpello and Campbell, 1983).

Data obtained with EMA was pre-processed prior to further analyses as follows: Momentary ratings of the two intrinsic items and the identified regulation item were averaged to compute a single momentary variable of autonomous motivation. To compute a single variable of controlled motivation, the average of momentary ratings of the two external regulation items and the introjected regulation item was calculated. Daily aggregates of autonomous and controlled motivation were subsequently used for further analyses.

\section{Study procedures}

Enrolled participants were invited to attend individual face-to-face enrollment sessions delivered by $\mathrm{MH}$, held either at their workplace or on the premises of the University of Helsinki. Each participant received a study specific unique ID and password for the online 
baseline assessment and the EMA app. After completing the baseline assessment electronically, participants took part in interviews to be introduced to the measurement process, to assess their understanding of the EMA questions. Interviews were recorded and lasted maximally 75 minutes, ensuring that the entire enrollment session was shorter than 90 minutes. At the conclusion of the enrollment session, participants were asked to install the EMA data collection app on their smartphone, and to enter their study ID number on the app's login screen, to allow anonymous linkage between their baseline assessment and EMA responses. All data were collected in the months October 2018 to February 2019.

\section{Analyses}

Data analysis was carried out using R statistics (v3.6.1). To study the effect of motivation on productivity and job satisfaction, network models were utilized (Package 'mlVAR' v0.4.3 in R, Espkamp et al., 2019). These network models can be used to explore relations between measured, time dependent variables. A network model can be seen as the visualization of the underlying multilevel models. The method allows for three different networks: between networks, indicating the differences between individuals, contemporaneous networks, indicating the within person effects within a given measurement (e.g., within a day with daily aggregates), and temporal networks, indicating the fixed effects found when using t to predict $\mathrm{t}+1$ (Epskamp, 2018).

These networks were calculated using a combination of partial correlation analyses and Bayesian networks. Supplementary material contains a reproducible example without personal data (see also Epskamp et al. 2019). This allowed for an estimation method that scaled up to eight variables (nodes) and acceptable up to 20 variables, which was sufficient for the current application. For the current estimation, the default settings were used, allowing for estimation using lmer as estimator, and allowing random effects to be correlated rather 
than orthogonal. Using the mlVAR models, random effects were extracted to create individual networks, for which contemporaneous and temporal networks were visualized.

Of the networks mentioned, only for the temporal network a clear temporal relation may be found. For the between-person and contemporaneous (within-person) networks, the relation is estimated both ways: from variable $\mathrm{A}$ to $\mathrm{B}$, and from variable $\mathrm{B}$ to $\mathrm{A}$, taking into account the effect of all other variables on this relation. As such, this results in one partial correlation, but two associated p-values. As the present study was intended to discover which relations may be present, a significant relation was assumed if one of the p-values is below 0.05. Moreover, for the individual networks, no significance was calculated due to the complications that would add to the method.

\section{Post-hoc tests for sleep}

The relation between sleep, productivity and motivation was studied using mixed models (lme4 by Bates et al., 2014; lmerTest by Kuznetsova et al., 2017). We tested whether productivity predicts the quality of the following night of sleep and whether sleep quality predicts both the autonomous and controlled motivation the next day. In these models, we added random effects for the intercepts on the individual level.

\section{Results}

\section{Baseline characteristics}

To allow for a multilevel model with sufficient data, the network linking the aggregated mean per day for autonomous and controlled motivation to productivity and job satisfaction was selected from the individuals who completed at least 10 days with recordings of autonomous and controlled motivation, as well as ratings of their productivity \& job satisfaction. This resulted in 14 included individuals (table 1) with an average of 23 complete days and over 1300 measurement points. Five participants were excluded due to insufficient data. 
*** INSERT TABLE 1 ABOUT HERE ***

\section{Between person group level outcomes}

Figure 1 shows the significant group level between person relations based on the between network.

*** INSERT FIGURE 1 ABOUT HERE ***

\section{Within person group level outcomes within the same day}

Figure 2 shows the group level within person relations based on the contemporaneous network. The association between productivity and job satisfaction was significant. The association between autonomous motivation and productivity was negative $(p=0.06)$. The association between controlled motivation and productivity was positive $(p=0.055)$.

*** INSERT FIGURE 2 ABOUT HERE ***

\section{Lagged within person group level outcomes (temporal networks)}

Figure 3 shows the significant lagged group level within person relations (temporal network).

*** INSERT FIGURE 3 ABOUT HERE ***

\section{Individual network models}

For the individual networks only negative relations stronger than -0.1 and positive relations stronger than 0.1 are discussed. For 12 out of the 14 individuals, the average 
autonomous motivation for tasks of that day was negatively related to self-reported productivity at the end of the day (partial $r$ 's from -0.12 to -0.20 ) whereas for each of the 14 individuals the average controlled motivation for the tasks during the day was positively related to self-reported productivity (partial $r$ 's from 0.12 to 0.17 ). In turn, productivity at the end of a day was negatively related to next day autonomous (partial $r$ 's from -0.13 to -0.22 ) and controlled task motivation (partial $r$ 's from -0.18 to -0.36 ) for all individuals.

In 6 out of 14 individuals, autonomous motivation during the day was positively related to job satisfaction at the end of the day (partial $r$ 's from 0.11 to 0.29 ). For all 14 individuals, controlled motivation during the day was not related to job satisfaction at the end of the day. Job satisfaction at the end of a day was positively related to autonomous motivation the next day for 8 individuals (partial $r$ 's from 0.10 to 0.14 ) and controlled motivation the next day for all 14 individuals (partial $r$ 's from 0.18 to 0.40 ).

\section{Post hoc testing}

We conducted additional analyses to provide more insight into the negative temporal relation between productivity (day $t$ ) and motivation the next day $(t+1)$. More specifically we tested the idea that poor sleep after a highly productive day might partly explain low motivation the next day. First, we assessed the relation between productivity (day t) and sleep quality reported the following morning $(\mathrm{t}+1)$. Subsequently, we assessed the relation between sleep quality and both autonomous and controlled motivation. Productivity rated at the end the day was not significantly related to the subsequent nights' sleep quality $(p=0.78)$. Yet, self-reported sleep quality was significantly positively associated with participant's autonomous motivation for the coming day $\left(\mathrm{t}_{339}=3.35, p<.001\right)$, whereas no significant association with controlled motivation was found $(p=0.10)$.

\section{Discussion}


This study investigated, at the between-persons, within-persons, and individual levels, the extents to which self-reported motivation during a day predicts self-rated productivity and job satisfaction at the end of the day, as well as how the latter two predicted next day motivation. Outcomes varied substantially across the different analysis approaches and are not fully consistent with self-determination theory (SDT; Ryan \& Deci, 2000), which states that higher levels of autonomous motivation should be related to more positive work-related outcomes, whereas controlled motivation should lead to less favorable outcomes.

\section{Discussion of the main findings}

In the present study, at group level between persons, autonomous motivation was positively associated with productivity, but unrelated to job satisfaction. Controlled motivation was neither associated with productivity nor with job satisfaction. At group level within persons, autonomous and controlled motivation were not associated with self-reported productivity or job satisfaction at the end of that day. In the individual network models autonomous motivation during the day was generally negatively related to self-reported productivity of that day and in six out of the 14 individuals positively related to job satisfaction. Controlled motivation during the day was consistently positively related to selfreported productivity of that day and consistently unrelated to job satisfaction of that day. In turn, productivity at the end of a day was consistently negatively related to next day autonomous and controlled task motivation. In contrast, job satisfaction at the end of the day was generally positively related to next day autonomous task motivation and consistently positively related to next day controlled task motivation. All in all, the outcomes of the present study are somewhat at odds with previous research showing that, in line with selfdetermination theory, higher levels of autonomous motivation are related to better workrelated outcomes such as productivity and job satisfaction whereas higher levels of controlled 
motivation are suggested to lead to less favourable outcomes (Richer et al., 2002; Gagné \& Deci, 2005; Gagné et al., 2010; Howard, et al, 2016; Kuvaas et al., 2017).

The discrepancy with prior research may be related to variable specificity and timescales studied. Survey studies typically use scales to tap into an individual's overall work motivation (e.g., how motivated they are in general or in the past weeks/months), as well as summary measures of productivity and job satisfaction over a longer period of time (e.g., Richer et al., 2002, Gagné et al., 2010; 2015; Kuvaas et al., 2017). The present study however focused on motivation for a specific work task at hand, and day-level satisfaction and productivity. In line with goal theory (Cropanzano et al., 1993; Liberman \& Trope, 1998; Unsworth et al., 2011; Gollwitzer 2012), individuals may answer motivation questions differently when they have a an abstract value or general desire in mind than when they have a task to complete. Correspondingly, an explanation for the present studies' findings may be that when people are completing tasks in their daily routine, due to time pressure, feasibility, and a focus on implementing (rather than thinking about the lofty goal), controlled motivation may become more highly related to productivity than is observed in previous survey based research using a between-person approach (Gagné and Deci, 2005; Cerasoli et al., 2014; Kuvaas et al., 2017).

The discrepancy with prior research may further arise from a difference between daily self-rated productivity as was assessed in the current study versus overall job performance which is commonly used in previous research (Gagné and Deci, 2005; Cerasoli et al., 2014; Kuvaas et al., 2017). In the latter, individuals (or their supervisor) are often asked if the individual does their job well (in general), meets the job requirements, are flexible at work, proactive, good team players, and so forth (Carpini, Parker, \& Griffin, 2017). Focussing on daily productivity may at least to some extent explain why results show relatively stronger associations with controlled than autonomous motivation, as compared to prior research on 
motivation and job performance (Gagné and Deci, 2005; Cerasoli et al., 2014; Kuvaas et al., 2017). Accordingly, in the present study doing something for a reward or to avoid punishment or because someone demands you to do something (controlled motivation) may have made participants 'feel' more productive. Whereas being motivated through pleasure, interest, and/or meaning (autonomous motivation), regardless of the effort put in, may have never been enough and hence 'felt' less productive.

Another difference with previous studies is that they had much larger participant samples ranging from 122 up to 4518 (Richer et al., 2002, Gagné \& Deci, 2005; Gagné et al., 2010; Kuvaas et al., 2017). It is possible that the small sample of 14 participants is the reason for the discrepancy with previous studies, although each of these participants on average completed 23 days of data, essentially providing a dataset of 322 comparisons of motivation to productivity and job satisfaction, yet nested within 14 individuals. Finally, it should be noted that previous between-person studies have used longer, validated scales of the constructs, whereas EMA studies are bound to rely on short, one-item scales of the constructs, with less than optimal reliability and validity. Yet, the between-person group level findings on the aggregate levels of autonomous motivation and productivity suggest these concerns may not be valid, as the observed association between autonomous motivation and productivity is in line with previous research (Gagné and Deci, 2005; Kuvaas et al., 2017).

In addition to the abovementioned methodological differences with prior betweenperson research, analysing associations at different levels of analyses (between-persons, within-persons, individual networks) may produce different results. Whereas a significant association between autonomous motivation and productivity between-person was observed, at the group level within persons, motivation during work tasks (autonomous or controlled) was not associated with self-reported productivity or job satisfaction at the end of that day. In fact, the group level within-person association between autonomous motivation and 
productivity was negative (borderline significant) whereas the association between controlled motivation and productivity was positive (again borderline significant). Importantly, these patterns were reflected in almost all of the individual models. Taken together, these findings illustrate it might be unwise to exclusively base best-practice guidelines aimed to promote motivation, productivity, and job satisfaction, on statistical inferences from aggregated data across large samples. This is in line with the ongoing discussion that generalizing conclusions based on between-persons group level data to individual participants may be worryingly imprecise (e.g., Fisher et al., 2018). The results further underscore the value of an individualized approach to studying occupational behavior and wellbeing (Binnewies et al., 2010; Dalal et al., 2014; Bakker, 2015; Ilies et al., 2015).

\section{Temporal relations in one-day lagged analyses}

The present study also investigated temporal relations using a one-day lag. At the group level within persons, job satisfaction (rated at the end of the day) was not associated with autonomous motivation, but was positively associated with next day controlled motivation. In the individual models, job satisfaction was positively associated with (a) autonomous motivation the next day for 8 out of 14 individuals (partial $r$ 's from 0.10 to 0.14 ) and with (b) controlled motivation the next day for each of the 14 individuals (partial $r$ 's from 0.18 to 0.40 ). These results suggest that when individuals are more satisfied with their job at the end of a given day, it increases the extent to which they are willing to do something for others, to obtain rewards or avoid punishments, or for self-worth related concerns the next day; more so, than the extent to which they do something because it is joyful, interesting, and/or meaningful to them the next day. Since job satisfaction is an expression of approval of a work environment (Locke, 1976), it stands to reason that if an individual is satisfied with their job when reflecting on their workday, they are more likely to be more motivated at work the following day. This is in agreement with a daily diary study reporting that, at the 
intraindividual level, job satisfaction predicted reports of organizational citizenship behaviors over time (Ilies et al., 2006). Our study extends these findings by illustrating a 1-day lagged, within person relation of daily job satisfaction to next day motivation.

Noteworthy is also the observation that self-reported productivity was negatively associated with next day autonomous and controlled motivation. In post-hoc analyses we tested the idea that poor sleep after a highly productive day might partly explain low motivation the next day. Productivity rated at the end of the day was however not related to sleep quality in the subsequent night, excluding poor sleep as an explanation. Further, though it may be tempting to suggest that productivity has a 'motivation flattening' effect, the observed associations are not causal relations. An alternative explanation might be natural altering of work tasks. For instance, if one completes a major and effort-requiring undertaking at work, he or she may feel highly productive at the end of the day. The next day, it might actually be healthy - or necessary from the perspective of one's work - to perform work tasks that are not that demanding and engaging right away, such as more "routine tasks" which may receive lower motivation ratings. As such, the observed association between productivity and motivation the next day may also reflect a pattern of work (task) organisation over time and actually be a healthy self-regulatory recovery pattern or a naturally occurring work pattern. Though speculative, it may also be seen as 'reducing demands' as a form of job crafting, which has previously been shown to relate to lower work engagement, an indicator of motivation (Demerouti et al, 2015).

\section{Strengths and weaknesses of the present study}

Whereas the majority of studies investigating self-determined motivation in relation to work related outcomes have utilized single or a few measurement points and have only examined between-persons relations (e.g., Richer et al, 2002; Otis \& Pelletier, 2005; Gagné et al., 2010; 2015, Kuvaas et al, 2017) the present study employed an intensive longitudinal 
design (EMA) and predominantly took a within-person approach. A strength of the present study is that office workers' work-related motivation, productivity and job satisfaction were frequently and repeatedly assessed as opposed to the most common applied pre-post measurements. The fourteen individuals included in the analyses had completed an average of 23 days' worth of ratings of motivation, productivity, and job satisfaction. Using advanced statistical techniques including multilevel and network models, the data allowed for withinperson analyses as well as individual networks of temporal relations between autonomous or controlled motivation, productivity and job satisfaction, which to our knowledge, has not been done previously. Another strength of the study is that it was conducted in real life, providing data with high ecological validity. Furthermore, in contrast to using surveys that ask participants to rate their motivation and work related outcomes 'in general' or over a specific retrospective period, which is prone to retrospective bias, with EMA the data were collected close in time to experience, limiting retrospective bias.

At the same time, the study also has several limitations. Although data were collected intensively within persons, only 19 individuals were included, of whom 14 completed sufficient assessments to perform the planned analyses. This is a small sample size for between-persons analyses and may in part explain why at the between-persons analyses (Figure 1), we found no statistically significant association between autonomous motivation and job satisfaction, as has been reported by others (e.g. Richer et al., 2002; Gagné et al., 2010). Further, only productivity and job satisfaction were assessed as work-related outcomes, whereas other studies have also focused on organizational commitment (Kuvaas et al., 2017), future work intention (Otis \& Pelletier, 2005), and emotional exhaustion (Richer et al., 2002). Also, whereas others have used supervisor ratings of employees' productivity (e.g., Kuvaas et al., 2017), in the present study productivity was measured by self-report, which may be subject to social desirability or inaccuracy, as individuals may not be able to reliably 
evaluate their productivity. Another limitation is that motivational orientations were aggregated to autonomous and controlled motivation, which may have obscured relations between specific motivational orientations and work-related outcomes. For example, one study found that performance was more strongly correlated to identified than to intrinsic motivation (Gagné et al 2015). Another limitation - inherent to all EMA studies - is the difficulty of using comprehensive scales of the psychological constructs and other variables. EMA necessitates using short, even one-item scales, whereas cross-sectional studies enable using validated scales, tapping into the multifaceted nature of the theoretical constructs. Indeed, while EMA allowed us to study task-related motivation with a much higher timeresolution than survey-based studies, task characteristics (e.g. task complexity) were not specified. This is an unfortunate trade-off, as previous research highlights the relevance of including task characteristics when studying the quality of motivation in relation to job performance (Gagné and Deci, 2005). Further, the item measuring extrinsic motivation ("I am working on this task because the situation requires me to"; Ketonen et al. 2018) may not be tapping into the essence of the construct, as the person may fully endorse "what the situation requires' for autonomous reasons. An optimal operationalization would perhaps tap more into the felt social pressure as the driver of the behavior.

In terms of the model used, we should be mindful of the limitations brought about by the assumptions made. For example, there is no reason to assume lags beyond one day carry no effect on subsequent moments, that cumulative poor sleep has no effect, or that the effects do not vary in time (Bringmann et al., 2017). In addition, there is little reason to assume that the effects are linear, i.e. inputs are proportional to outputs, multivariate normality does not self-evidently hold in many cases, and the autocorrelation function might not be stationary over time, confounding the results (Kelty-Stephen et al., 2013; Kelty-Stephen \& Wallot, 2017). To relax these assumptions, more within-individual data would be needed, but a 
promising alternative avenue would be a shift to (e.g. recurrence based) methods for analysing multivariate time series data, which do not require the aforementioned assumptions

(Hasselman \& Bosman, 2020).

\section{Implications / Future perspectives}

The present study used a novel approach to study the association between motivation and work related outcomes. Above all, this approach should be considered complementary to the frequently used between person approach in large cross sectional or cross-lagged studies which, in line with SDT (Ryan \& Deci, 2000), have shown that higher levels of autonomous motivation are related to more positive work related outcomes (e.g., Richer et al, 2002; Otis \& Pelletier, 2005; Gagné et al., 2015, Kuvaas et al, 2017). The present study illustrates that this relation may differ, especially when intensive time-series data are analyzed using a withinperson or individual networks approach, and when the motivation is conceptualized at lowerlevel i.e. momentary task motivation rather than a generalized work motivation construct. This may stimulate researchers in this field to take such approaches more into account. For example, future studies focusing on within person processes and individual networks may also include variables such as emotional exhaustion (Richer et al., 2002), future work intention (Otis \& Pelletier, 2005), work engagement (Demerouti et al., 2015; Bakker and Oerlemans, 2019), and organizational commitment (Kuvaas et al., 2017). Elucidating the relevant mechanisms at the individual level is necessary to develop and test personalized interventions.

Another suggestion for future research is to combine more traditional survey based approaches with EMA in the same participants. That way, using validated scales and tapping into the multifaceted nature of the theoretical constructs can be combined with daily assessments for within person relations and temporal dynamics. Calls for such research have also been made by others (e.g. Bakker et al., 2015; Ilies et al., 2015). Finally, many of these perspectives converge to moving into a complex systems approach, which has been 
previously applied in occupational health (Navarro \& Arrieta, 2010; Navarro \& Rueff-Lopes, 2015; Ceja \& Navarro, 2017) and is now being applied to self-determined motivation processes (Heino et al., 2020).

\section{Conclusion}

Previous research on work related motivation and work-related outcomes, often employing single or few measurement time points and between-person approaches, has related autonomous motivation to higher job satisfaction and productivity, and controlled motivation to worse outcomes. Using ecological momentary assessment, within-person, and individual network modelling, this study could not replicate these findings, raising the question whether these relations hold within persons over time. More research within persons is needed to address this question and to pave the way for personalized interventions to improve work-related outcomes. 


\section{References}

Bakker, A. B. (2015). Towards a multilevel approach of employee well-being. European Journal of Work and Organizational Psychology, 24(6), 839-843.

Bakker, A. B., \& Oerlemans, W. G. (2019). Daily job crafting and momentary work engagement: A self-determination and self-regulation perspective. Journal of Vocational Behavior, 112, 417-430.

Bates, D., Mächler, M., Bolker, B., \& Walker, S. (2014). Fitting linear mixed-effects models using lme4. arXiv preprint arXiv:1406.5823.

Binnewies, C., Sonnentag, S., \& Mojza, E. J. (2010). Recovery during the weekend and fluctuations in weekly job performance: A week-level study examining intraindividual relationships. Journal of Occupational and Organizational Psychology, 83(2), 419-441.

Bowling, N. A., Beehr, T. A., Wagner, S. H., \& Libkuman, T. M. (2005). Adaptation-level theory, opponent process theory, and dispositions: An integrated approach to the stability of job satisfaction. Journal of Applied Psychology, 90, 1044-1053.

Bringmann, L. F., Hamaker, E. L., Vigo, D. E., Aubert, A., Borsboom, D., \& Tuerlinckx, F. (2017). Changing dynamics: Time-varying autoregressive models using generalized additive modeling. Psychological Methods, 22(3), 409.

Cappelleri, J. C., Bushmakin, A. G., McDermott, A. M., Sadosky, A. B., Petrie, C. D., \& Martin, S. (2009). Psychometric properties of a single-item scale to assess sleep quality among individuals with fibromyalgia. Health and quality of life outcomes, 7(1), 54

Carpini, J. A., Parker, S. K., \& Griffin, M. A. (2017). A look back and a leap forward: A review and synthesis of the individual work performance literature. The Academy of Management Annals, 11(2), 825-885. 
Ceja, L., \& Navarro, J. (2017). Redefining flow at work. In Flow at Work (pp. 81-105). Routledge.

Cerasoli, C. P., Nicklin, J. M., \& Ford, M. T. (2014). Intrinsic motivation and extrinsic incentives jointly predict performance: A 40-year meta-analysis. Psychological bulletin, 140(4), 980.

Cropanzano, R., James, K., \& Citera, M. (1993). A goal hierarchy model of personality, motivation, and leadership. Research in organizational behavior, 15, 267-322.

Csikszentmihalyi, M., \& Larson, R. (1992). Validity and Reliability of the Experience Sampling Method, de Vries, M.(toim.). The Experience of Psychopathology, 43-57.

Dalal, R. S., Bhave, D. P., \& Fiset, J. (2014). Within-person variability in job performance: A theoretical review and research agenda. Journal of Management, 40(5), 1396-1436.

Dalal, R. S., Alaybek, B., \& Lievens, F. (2020). Within-Person Job Performance Variability Over Short Timeframes: Theory, Empirical Research, and Practice. Annual Review of Organizational Psychology and Organizational Behavior, 7, 421-449.

Debusscher, J., Hofmans, J., \& De Fruyt, F. (2016). Do personality states predict momentary task performance? The moderating role of personality variability. Journal of Occupational and Organizational Psychology, 89(2), 330-351. doi: $10.1111 /$ joop.12126

Deci, E. L., Olafsen, A. H., \& Ryan, R. M. (2017). Self-determination theory in work organizations: The state of a science. Annual Review of Organizational Psychology and Organizational Behavior, 4, 19-43.

Demerouti, E., Bakker, A. B., \& Halbesleben, J. R. (2015). Productive and counterproductive job crafting: A daily diary study. Journal of Occupational Health Psychology, 20(4), 457.

Epskamp, S., Waldorp, L. J., Mõttus, R., \& Borsboom, D. (2018). The Gaussian graphical 
model in cross-sectional and time-series data. Multivariate Behavioral Research, 53(4), 453-480.

Epskamp, S., Deserno, M.K., \& Bringmann, L.F. (2019). mlVAR: Multi-Level Vector Autoregression. R package version 0.4.3. https://CRAN.Rproject.org/package $=$ mlVAR

Fahrenberg, J., \& Myrtek, M. (1996). Ambulatory assessment. Göttingen: Hogrefe.

Fisher, A. J., Medaglia, J. D., \& Jeronimus, B. F. (2018). Lack of group-to-individual generalizability is a threat to human subjects research. Proceedings of the National Academy of Sciences, 115(27), E6106-E6115.

Gagné, M., \& Deci, E. L. (2005). Self-determination theory and work motivation. Journal of Organizational behavior, 26(4), 331-362.

Gagné, M., Forest, J., Gilbert, M. H., Aubé, C., Morin, E., \& Malorni, A. (2010). The motivation at work scale: Validation evidence in two languages. Educational and psychological measurement, 70(4), 628-646.

Gagné, M., Forest, J., Vansteenkiste, M., Crevier-Braud, L., Van den Broeck, A., Aspeli, A. K., ... \& Halvari, H. (2015). The Multidimensional Work Motivation Scale: Validation evidence in seven languages and nine countries. European Journal of Work and Organizational Psychology, 24(2), 178-196.

Gagné, Tian, A., M., \& Soo, C., Wang, B., Ho, K. S. B., \& Hosszu, K. (2019). Different motivations for knowledge sharing and hiding: The role of motivating work design. Journal of Organizational Behavior, 40(7), 783-799.

Gollwitzer, P. (2012). Mindset theory of action phases (pp. 526-545).

Hamaker, E. L. (2012). Why researchers should think "within-person": A paradigmatic rationale. In M. R. Mehl \& T. S. Conner (Eds.), Handbook of research methods for studying daily life (pp. 43-61). New York, NY, US: The Guilford Press. 
Hamaker, E. L., \& Wichers, M. (2017). No time like the present: Discovering the hidden dynamics in intensive longitudinal data. Current Directions in Psychological Science, $26(1), 10-15$.

Hasselman, F., \& Bosman, A. M. (2020). Studying Complex Adaptive Systems with Internal States: A Recurrence Network Approach to the Analysis of Multivariate Time Series Data Representing Self-Reports of Human Experience. Frontiers in Applied Mathematics and Statistics, 6, 9.

Heino, M. T. J., Knittle, K. P., Noone, C., Hasselman, F., \& Hankonen, N. (2020). Studying behaviour change mechanisms under complexity [Preprint]. PsyArXiv. https://doi.org/10.31234/osf.io/fxgw4

Howard, J., Gagné, M., Morin, A. J., \& Van den Broeck, A. (2016). Motivation profiles at work: A self-determination theory approach. Journal of Vocational Behavior, 95, 7489.

Ilies, R., \&Judge, T. A. (2002). Understanding the dynamic relationships among personality, mood, and job satisfaction: A field experience sampling study. Organizational Behavior and Human Decision Processes, 89, 1119-1139. doi:10.1016/S07495978(02)00018-3

Ilies, R., \& Judge, T. A. (2004). An experience-sampling measure of job satisfaction and its relationships with affectivity, mood at work, job beliefs, and general job satisfaction. European Journal of Work and Organizational Psychology, 13, 367-389. doi:10.1080/13594320444000137

Ilies, R., Scott, B. A., \& Judge, T. A. (2006). The interactive effects of personal traits and experienced states on intraindividual patterns of citizenship behavior. Academy of Management Journal, 49(3), 561-575. 
Ilies, R., Aw, S. S., \& Pluut, H. (2015). Intraindividual models of employee well-being: What have we learned and where do we go from here?. European Journal of Work and Organizational Psychology, 24(6), 827-838.

Judge, T. A., Simon, L. S., Hurst, C., \& Kelley, K. (2014). What I experienced yesterday is who I am today: Relationship of work motivations and behaviors to within-individual variation in the five-factor model of personality. Journal of Applied Psychology, 99(2), $199-221$.

Kanfer, R., Frese, M., \& Johnson, R. E. (2017). Motivation related to work: A century of progress. Journal of Applied Psychology, 102(3), 338.

Kelty-Stephen, D. G., Palatinus, K., Saltzman, E., \& Dixon, J. A. (2013). A Tutorial on Multifractality, Cascades, and Interactivity for Empirical Time Series in Ecological Science. Ecological Psychology, 25(1), 1-62. https://doi.org/10.1080/10407413.2013.753804

Kelty-Stephen, D. G., \& Wallot, S. (2017). Multifractality Versus (Mono-) Fractality as Evidence of Nonlinear Interactions Across Timescales: Disentangling the Belief in Nonlinearity From the Diagnosis of Nonlinearity in Empirical Data. Ecological Psychology, 29(4), 259-299. https://doi.org/10.1080/10407413.2017.1368355

Ketonen, E. E., Dietrich, J., Moeller, J., Salmela-Aro, K., \& Lonka, K. (2018). The role of daily autonomous and controlled educational goals in students' academic emotion states: An experience sampling method approach. Learning and Instruction, 53, 10-20.

Kühnel, J., Bledow, R., \& Feuerhahn, N. (2016). When do you procrastinate? Sleep quality and social sleep lag jointly predict self-regulatory failure at work. Journal of Organizational Behavior, 37(7), 983-1002.

Kühnel, J., Sonnentag, S., Bledow, R., \& Melchers, K. G. (2018). The relevance of sleep and 
circadian misalignment for procrastination among shift workers. Journal of Occupational and Organizational Psychology, 91(1), 110-133.

Kuvaas, B., Buch, R., Weibel, A., Dysvik, A., \& Nerstad, C. G. (2017). Do intrinsic and extrinsic motivation relate differently to employee outcomes?. Journal of Economic Psychology, 61, 244-258.

Kuznetsova, A., Brockhoff, P. B., \& Christensen, R. H. B. (2017). lmerTest package: tests in linear mixed effects models. Journal of statistical software, 82(13).

Levesque, C., \& Brown, K. W. (2007). Mindfulness as a moderator of the effect of implicit motivational self-concept on day-to-day behavioral motivation. Motivation and Emotion, 31(4), 284-299.

Liberman, N., \& Trope, Y. (1998). The role of feasibility and desirability considerations in near and distant future decisions: A test of temporal construal theory. Journal of Personality and Social Psychology, 75, 5-18.

Locke, E. A. (1976). The nature and causes of job satisfaction. In M. D. Dunnette (Ed.), Handbook of industrial and organizational psychology (pp. 1297-1343). Chicago, IL: Rand McNally.

Mehl, M. R., \& Conner, T. S. (2012). Handbook of research methods for studying daily life. New York, NY: Guilford Press.

Merlo, K. L., Shaughnessy, S. P., \& Weiss, H. M. (2018). Affective influences on withinperson changes in work performance as mediated by attentional focus. European Journal of Work and Organizational Psychology, 27(1), 126-139.

Milette, V., \& Gagné, M. (2008). Designing volunteers' tasks to maximize motivation, satisfaction and performance: The impact of job characteristics on the outcomes of volunteer involvement. Motivation and Emotion, 32(1), 11-22. 
Navarro, J., \& Arrieta, C. (2010). Chaos in human behavior: The case of work motivation. The Spanish Journal of Psychology, 13(1), 244-256.

Navarro, J., \& Rueff-Lopes, R. (2015). Healthy variability in organizational behavior: Empirical evidence and new steps for future research. Nonlinear Dynamics, Psychology, and Life Sciences, 19(4), 529-552.

Ng, J. Y., Ntoumanis, N., Thøgersen-Ntoumani, C., Deci, E. L., Ryan, R. M., Duda, J. L., \& Williams, G. C. (2012). Self-determination theory applied to health contexts: A metaanalysis. Perspectives on Psychological Science, 7(4), 325-340.

Otis, N., \& Pelletier, L. G. (2005). A Motivational Model of Daily Hassles, Physical Symptoms, and Future Work Intentions Among Police Officers 1. Journal of Applied Social Psychology, 35(10), 2193-2214.

R Core Team (2019). R: A language and environment for statistical computing. R Foundation for Statistical Computing, Vienna, Austria. URL https://www.R-project.org/.

Richer, S. F., Blanchard, C., \& Vallerand, R. J. (2002). A motivational model of work turnover. Journal of Applied Social Psychology, 32(10), 2089-2113.

Ryan, R. M., \& Deci, E. L. (2000). Self-determination theory and the facilitation of intrinsic motivation, social development, and well-being. American psychologist, 55(1), 68.

Scarpello, V., \& Campbell, J. P. (1983). Job satisfaction: Are all the parts there? Personnel Psychology, 36, 577-600.

Schelvis, R. M., Hengel, K. M. O., Wiezer, N. M., Blatter, B. M., van Genabeek, J. A., Bohlmeijer, E. T., \& van der Beek, A. J. (2013). Design of the Bottom-up Innovation project-a participatory, primary preventive, organizational level intervention on workrelated stress and well-being for workers in Dutch vocational education. BMC public health, 13(1), 760 .

Spruijt-Metz, D., Nilsen, W., \& Pavel, M. (2014). mHealth for behavior change and 
monitoring. In mHealth multidisciplinary verticals (pp. 141-154). CRC Press.

Stenius, M., Hankonen, N., Ravaja, N., \& Haukkala, A. (2016). Why share expertise? A closer look at the quality of motivation to share or withhold knowledge. Journal of Knowledge Management, 20(2), 181-198.

Stone, A. A., \& Shiffman, S. (1994). Ecological momentary assessment (EMA) in behavorial medicine. Annals of Behavioral Medicine, 16(3), 199-202.

Unsworth, K., Adriasola, E., Johnston-Billings, A., Dmitrieva, A., \& Hodkiewicz, M. (2011). Goal hierarchy: Improving asset data quality by improving motivation. Reliability Engineering \& System Safety, 96(11), 1474-1481.

Vansteenkiste, M., Neyrinck, B., Niemiec, C. P., Soenens, B., De Witte, H., \& Van den Broeck, A. (2007). On the relations among work value orientations, psychological need satisfaction and job outcomes: A self-determination theory approach. Journal of occupational and organizational psychology, 80(2), 251-277. 
Table

Table 1. Participant characteristics

\begin{tabular}{|l|c|}
\hline$N$ & 14 \\
\hline Age in years, mean (SD) & $39(8.1)$ \\
\hline Sex & 9 Female, 2 Male, 3 not reported \\
\hline Job roles & HR / Recruitment consultant (10); \\
& Project manager (2); \\
& Safety manager (1); \\
& Designer (1) \\
\hline Years in role, mean (SD) & $3.3(3.1)$ \\
\hline Years in organization, mean (SD) & $9.8(10.3)$ \\
\hline
\end{tabular}




\section{Figures}

FIGURE 1

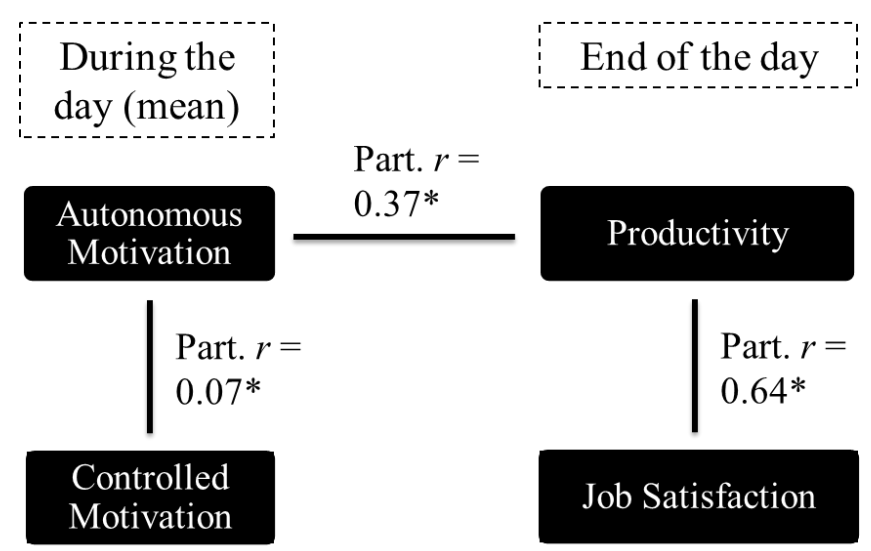

Figure 1. The group level between person relations (between network). Note: Only significant associations are shown. $P$ values: $*<0.05$. 
FIGURE 2

\section{Within the same day}

\section{During the day (mean)}

\section{Autonomous}

Motivation

\section{Controlled} Motivation

\section{End of the day}

Productivity

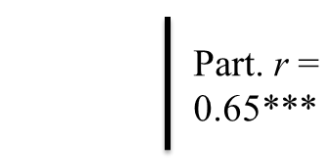

Job Satisfaction

Figure 2. The group level within person relations (contemporaneous network). Note: Only significant associations are shown. $P$ values: $* * *<0.001$ 
FIGURE 3

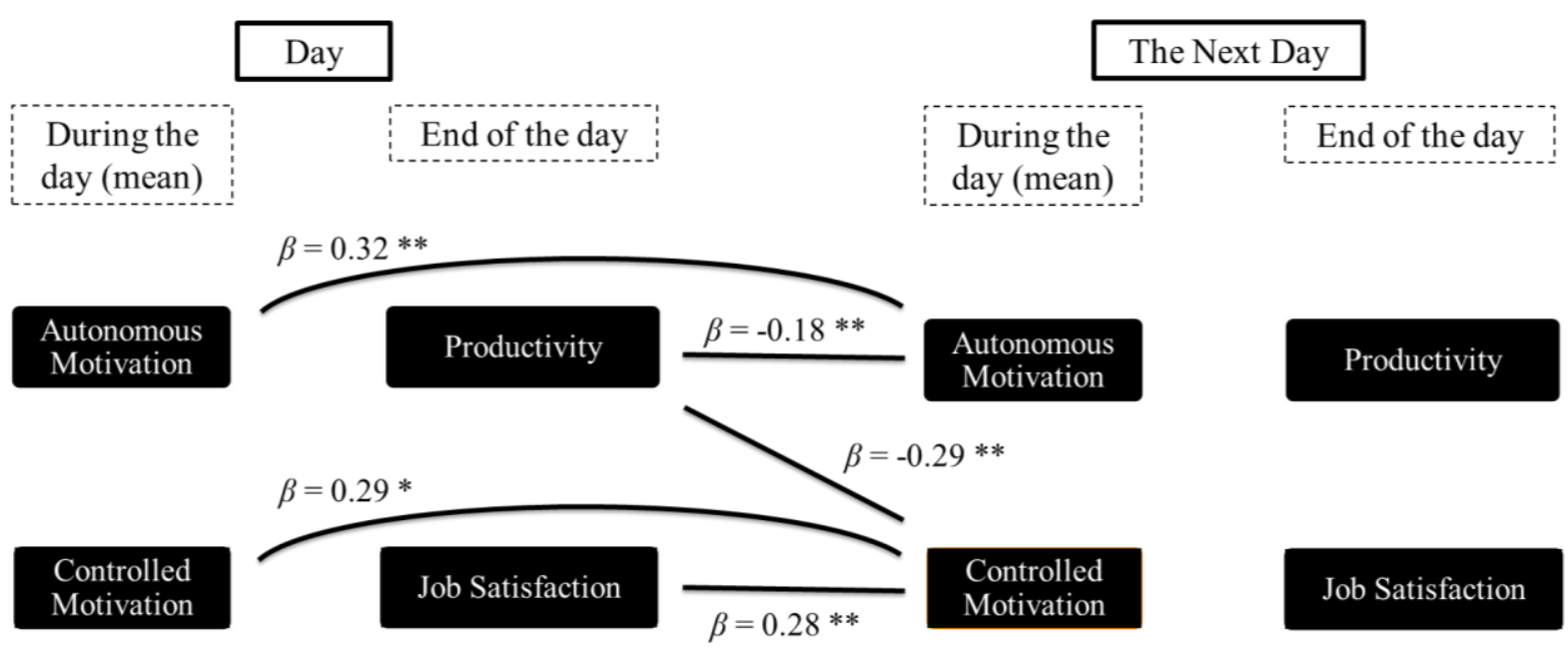

Figure 3. The lagged group level within person relations (temporal network). Note: Only significant associations are shown. $P$ values: $*<0.05 ; * *<0.01$. 